ISSN 0103-9954

\title{
ANÁLISE DA ESTRUTURA DA PAISAGEM DO PARQUE NACIONAL DO SUPERAGÜI - PR E SUA ZONA DE AMORTECIMENTO
}

\author{
THE LANDSCAPE STRUCTURE ANALYSIS OF NATINAL PARK OF \\ SUPERAGÜI, PARANÁ STATE AND THE BUFFER'S ZONE
}

Mayssa Mascarenhas Grise ${ }^{1}$ Daniela Biondi²

\begin{abstract}
RESUMO
O Parque Nacional do Superagüi está localizado no litoral norte do Estado do Paraná, maior área contínua remanescente de Floresta Atlântica do país, bioma este entre os mais ameaçados do mundo. Esta área abrange o litoral norte do Estado e compreende uma série de unidades de conservação de diferentes categorias, sendo a Área de Proteção Ambiental de Guaraqueçaba a de maior extensão, sobrepondo-se às demais. O presente trabalho teve como objetivo analisar a estrutura da paisagem (matriz e fragmentos) do PN do Superagüi e sua zona de amortecimento. A partir da classificação supervisionada da imagem digital Landsat $5 \mathrm{TM}$, foi feita a classificação da cobertura do solo da área e definidos os atributos de área e perímetro dos polígonos obtidos. Feita a análise da estrutura da paisagem, constatou-se que a matriz do Parque é formada por vegetação nativa interrompida pela presença de fragmentos. Cerca de $7 \%$ da área de estudo é formado por fragmentos, os quais pertencem às classes de vegetação alterada, solo descoberto, áreas urbanizadas, areia e água; em grande parte possuem menos de um hectare e têm forma regular. A zona de amortecimento do Parque não está totalmente inserida dentro dos limites da APA Federal de Guaraqueçaba, sendo que grande parte da zona de amortecimento é formada por áreas marinhas. Conclui-se que a análise da estrutura da paisagem, através de seus componentes estruturais matriz e fragmentos, é um subsídio eficaz para verificar a funcionalidade da cobertura do solo da UC e sua zona de amortecimento.
\end{abstract}

Palavras-chave: fragmento; matriz; Floresta Atlântica; Guaraqueçaba-PR.

\begin{abstract}
The National Park of Superagüi is located on the north coast of Paraná state. It is the largest continuous area of the Atlantic Forest remaining in the country and this biome is among the most threatened ones in the world. This area covers the north coast of the state and includes several conservation units of different categories, and the Environmental Protection Area of Guaraqueçaba, is the largest one. The objective of this study was to analyze the landscape structure (matrix and patches) of the National Park of Superaguii, and its buffer zone. The classification of land cover and the definition of the attributes of the area and perimeter were made using a digital image Landsat $5 \mathrm{TM}$. According to the landscape structure analysis, it was observed that the Park matrix is formed by native vegetation interrupted by the presence of patches. Approximately $7 \%$ of the studied area is composed by fragments, which belong to class of changed vegetation, exposed soil, urban areas, sand and water; mostly have less than one hectare and have a regular shape. The Park buffer zone is not fully incorporated within the limits of Environmental Protection Area of Guaraqueçaba, where marine areas form a great portion. It follows that landscape structure analysis, through its structural components matrix and patches, is an efficient subsidy to verify the park land cover functionality and its buffer zone.
\end{abstract}

Keywords: patches; matrix; Atlantic Forest; Guaraqueçaba.

1. Bióloga, Mestre em Engenharia Florestal, Rua Ponta Grossa, 330, Apto. 401, CEP 80610-160, Curitiba (PR). mayssagrise@ibest.com.br

2. Engenheira Florestal, Dra ${ }^{\mathrm{a}}$, Professora Associada III do Departamento de Ciências Florestais, Universidade Federal do Paraná, Av. Pref. Lothário Meissner, 900, Jardim Botânico, Campus III, CEP 80210-170, Curitiba (PR). dbiondi@ufpr.br

Recebido para publicação em 19/05/2009 e aceito em 20/01/2011

Ci. Fl., v. 22, n. 1, jan.-mar., 2012 


\section{INTRODUÇÃO}

O Estado do Paraná possui uma importante área contínua de Floresta Atlântica, bioma de maior biodiversidade do mundo e entre os mais ameaçados (IPARDES 2001). Uma das medidas para se preservar os remanescentes de áreas naturais, ao redor do Planeta, é a criação de áreas protegidas (BENSUSAN, 2006). No Brasil, o Sistema Nacional de Unidades de Conservação (SNUC) instituiu e normatizou as áreas protegidas em Unidades de Conservação (UC) (BRASIL, 2000). Assim, para tentar resguardar o remanescente da Floresta Atlântica paranaense, foi criada uma série de UCs das mais diversas categorias de manejo (SPVS, 1992; IPARDES, 2001). Dentre essas, está a Área de Proteção Ambiental (APA) Federal de Guaraqueçaba (BRASIL, 1989) e o Parque Nacional (PN) do Superagüi (BRASIL, 1985). A região é importante pela presença de espécies raras e ameaçadas de extinção, é área do complexo estuarino da Baía de Paranaguá, com sítios arqueológicos (sambaquis) e comunidades caiçaras integradas no ecossistema regional (SPVS, 1992; IPARDES, 2001).

As áreas decretadas como UCs são extremamente importantes, entretanto apenas sua criação documental não garante sua preservação. São necessários uma série de estudos, planejamentos e levantamentos para que uma UC contribua realmente para a conservação de um bioma (TOSSULINO et al., 2006).

Assim, nos anos 80, se consolidou uma ciência relativamente nova que estuda a paisagem de maneira aprofundada e global. Os precursores de estudos de ecologia da paisagem, Forman e Godron (1986) definem a paisagem como uma área de terra heterogênea e composta de agrupamentos de ecossistemas interligados que se repetem de forma similar, em todo lugar. As paisagens, assim definidas, são formadas por três elementos estruturais, a matriz, os fragmentos e os corredores. Estes podem ser avaliados e estudados de forma a contribuir para a manutenção de áreas protegidas, bem como na elaboração de planos de manejo e estratégias de conservação, não focando as UCs de forma isolada, mas considerando o ambiente como um todo.

A necessidade de conservação dos remanescentes de Floresta Atlântica do Brasil, e o aumento da efetividade das UCs existentes, são evidentes. Diante disto, o objetivo do presente trabalho foi verificar a funcionalidade da paisagem do PN do Superagüi a partir da análise dos elementos estruturais da paisagem, matriz e fragmentos e de sua Zona de Amortecimento.

\section{MATERIAL E MÉTODOS}

\section{Área de estudo - Parque Nacional do Superagüi}

O PN do Superagüi localiza-se no litoral norte do Estado do Paraná, no município de Guaraqueçaba (Figura 1). A área faz parte da maior parcela remanescente contínua de Floresta Atlântica do Brasil, floresta tropical entre as mais ameaçadas do Planeta, um banco genético de potencialidade desconhecida, de enorme riqueza de flora e fauna, rica em manguezais e uma das poucas áreas florestadas do Paraná, estado que perdeu mais de $95 \%$ de sua cobertura original (SPVS, 1992; IPARDES, 1995; IAP, 1999; IPARDES 2001). Inserido no domínio do Bioma Mata Atlântica, sua vegetação é caracterizada por duas formações fisionômicas e ecologicamente distintas: as áreas de Formações Pioneiras e a região de Floresta Ombrófila Densa. A fauna é rica em endemismos e espécies raras característica de ecossistema neotropical (IAP, 1999).

O Decreto $\mathrm{n}^{\circ} .97 .688$, de 25 de abril de 1989 - criou o PN do Superagüi formado pelas Ilhas da Peças e a do Superagüi, perfazendo $33.855 \mathrm{ha}$, com o objetivo de proteger e preservar amostra dos ecossistemas ali existentes, assegurando a preservação de seus recursos naturais, proporcionando oportunidades controladas para uso pelo público, educação e pesquisa científica (BRASIL, 1989). A área do PN do Superagüi também está inserida nos limites da APA Federal de Guaraqueçaba e da APA Estadual de Guaraqueçaba. O Parque foi ampliado em 1997 pela Lei $\mathrm{n}^{\circ}$. 9.513, quando foram agregadas, aos seus limites, as Ilhas de Pinheiro e Pinheirinho, as quais eram definidas como Área de Relevante Interesse Ecológico (ARIE). As Ilhas tiveram seu decreto revogado e passaram a integrar a área do Parque (BRASIL, 1985; BRASIL, 1997).

\section{Base de dados}

A análise da estrutura da paisagem foi realizada a partir de duas cenas do satélite Landsat 5 TM - cenas 220/077 e 220/078 (órbita/ponto), de 2 de setembro de 2002, com resolução espacial de 30 metros, cedida pela Secretaria de Estado do Meio 


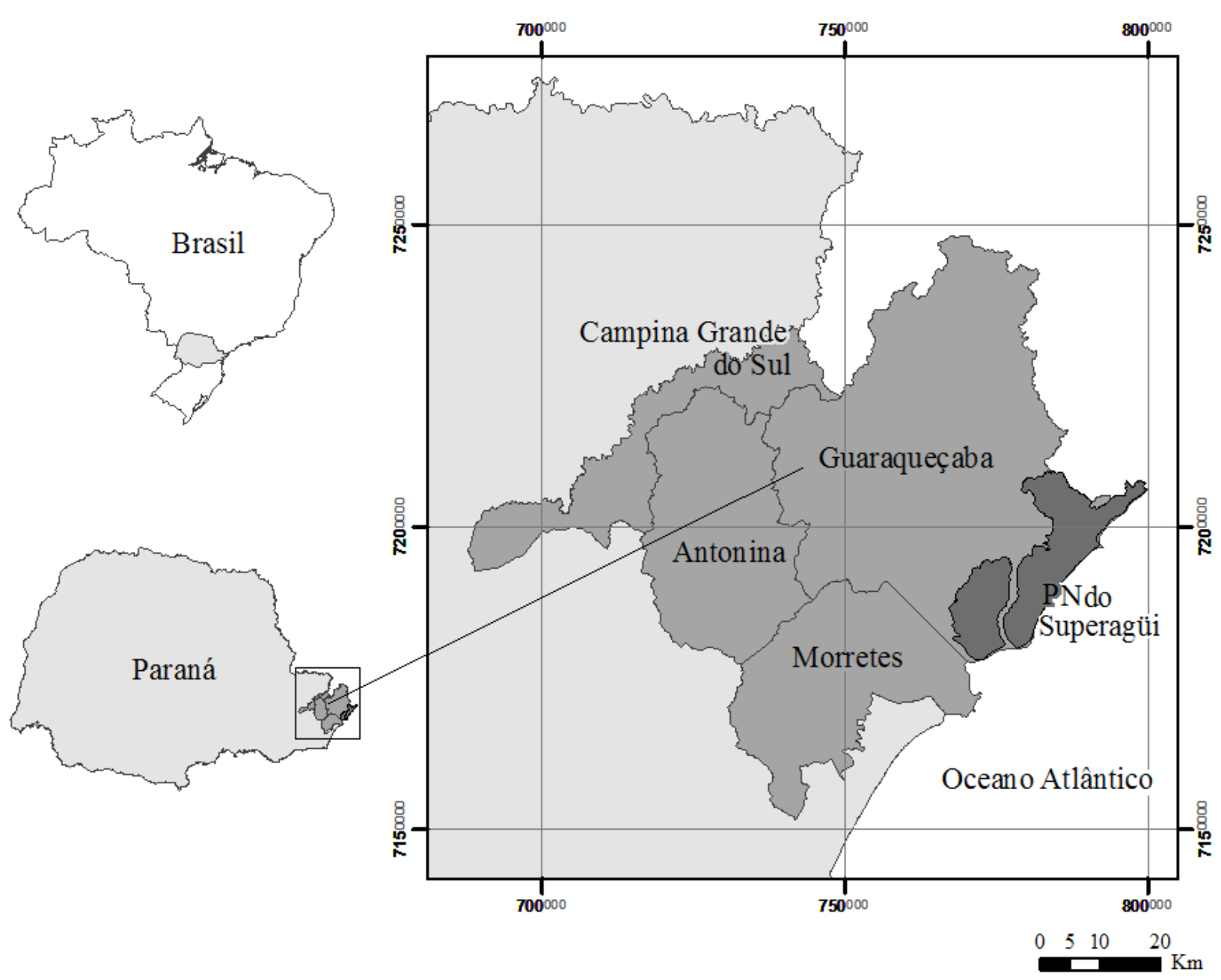

FIGURA 1: Localização da área de estudo (Guaraqueçaba, PR - Brasil).

FIGURE 1: Study area location (Guaraqueçaba, Paraná state - Brazil).

Ambiente - SEMA - Divisão de Geoprocessamento e Sensoriamento Remoto. Considera-se que o erro gráfico aceito em cartografia é de $0,2 \mathrm{~mm}$ e em sensoriamento remoto é de $1 / 2$ pixel. Para a resolução espacial de $30 \mathrm{~m}$ do satélite Landsat $5 \mathrm{TM}$, a escala de trabalho é de aproximadamente 1:75.000. Foram utilizadas cartas do IBGE do Estado do Paraná 1:50.000 e 1:100.000, cedidas também pela SEMA, escanerizadas e georreferenciadas. Os softwares utilizados em cada etapa de trabalho foram: ENVI 3.5 e MultiSpec Win32 para o processamento da imagem; ArcGis 9.1 para o processamento da imagem e cálculos de perímetro e área; Microsoft Office Excel 2003 para cálculos estatísticos.

\section{Procedimentos metodológicos}

Primeiramente foi feito o mosaico das duas cenas do satélite Landsat $5 \mathrm{TM}$ - cenas 220/077 e 220/078 (órbita/ponto). A área de estudo foi delimitada e recortada no software ENVI 3.5. A imagem obtida para a realização deste estudo passou pelo processo de correção da geometria a partir das cartas do IBGE do estado do Paraná 1:50.000 e $1: 100.000$.

A imagem foi submetida à correção geométrica e passou pela classificação digital supervisionada empregando-se o método da máxima verossimilhança e o software MultiSpec. Utilizaram-se amostras de treinamento para a definição das seguintes classes de cobertura do solo: vegetação nativa, vegetação nativa mangue, vegetação nativa sombreada, vegetação alterada, vegetação alterada cultura, áreas urbanizadas, solo descoberto, água e areia. A definição da classe areia a partir das amostras de treinamento não foi possível devido à sua resposta espectral e de determinadas áreas urbanizadas se confundirem. As áreas com areia foram definidas a partir da 
elaboração de uma máscara, utilizando-se dos Índices de Artificialidade DoA e NandA:

$$
D o A=\frac{G-R}{G+R} \quad \text { Nand } A=G-(R+B)
$$

Em que: $\mathrm{R}=$ intensidades dos pixels na banda verde vermelho; $\mathrm{G}=$ intensidades dos pixels na banda verde.

Para estimar a acurácia das amostras de treinamento foi realizada a avaliação através da matriz de confusão. Na matriz de confusão foi observada a condição de minimização dos erros de classificação das amostras de cada classe, de forma que a matriz não apresentasse valores fora da diagonal, ou seja, $100 \%$ de acerto de classificação para as amostras de cada classe. Após o processamento da classificação digital, a presença de pixels isolados foi suprimida utilizando-se um filtro de moda $3 \times 3$.

Após a filtragem, a imagem digital classificada no formato raster foi transformada em uma imagem vetorial (formato shape file) formando polígonos. A edição da imagem temática foi realizada atribuindo-se aos polígonos os atributos de classes de cobertura do solo incluindo a máscara com a classe areia e os atributos de área e perímetro.

O PN do Superagüi teve seu contorno (limites) digitalizado no software ArcGis 9.1. O delineamento da Unidade foi realizado a partir das descrições dos limites geográficos contidas no Decreto de criação da Unidade (BRASIL, 1989) e na lei $\mathrm{n}^{\circ} 9.513$ (BRASIL, 1997) que ampliou seus limites, com o apoio de cartas 1:50.000 e da imagem digital Landsat.

\section{Classes de cobertura do solo}

A imagem classificada foi editada, sendo definidas as seguintes classes de cobertura do solo:

a) água: áreas com presença de água;

b) vegetação nativa: áreas de vegetação natural com formação densa; foram incluídas as áreas de vegetação nativa sombreada e áreas de formação pioneira de influência fluviomarinha;

c) vegetação alterada: áreas de vegetação com alterações de densidade de cobertura vegetal, também as áreas de cultura; cobertura;

d) solo descoberto: áreas com o solo sem

e) áreas urbanizadas: áreas com presença de construções e asfalto; f) areia: áreas com presença de areia.

\section{Classes de área de cobertura}

As classes de área de cobertura foram definidas após a tabulação dos valores referentes à área dos polígonos. As classes variaram de fragmentos menores que 1,0 ha a fragmentos maiores que 100 ha. Utilizou-se o número de classes adequado aos resultados obtidos, sempre com variações decimais como segue: menor que 1,0 ha; de 1,0 a 10 ha; maior que 10 ha.

\section{Classes de perímetro}

As classes de perímetro basearam-se no índice de forma dos fragmentos. Este foi calculado baseado em Forman e Godron (1986) seguindo a fórmula:

$$
D=\frac{L}{2 \sqrt{A}}
$$

$\mathrm{A}=$ área

Em que: $\mathrm{D}$ = índice de forma; $\mathrm{L}=$ perímetro;

O menor valor possível para o índice de forma, representado pela letra "D", é 1,0 (um) que representa a forma mais circular que um polígono pode apresentar. As classes de perímetro foram definidas após os cálculos e tabulação do índice de forma de todos os polígonos. As classes variaram de fragmentos com menos de 1,13 de índice de forma a fragmentos maiores que 2,5 , como segue: menor que 1,5 ; de 1,5 a 2,0; maior que 2,0.

Também foram calculadas a Média, a Moda e a Mediana do índice de forma dos fragmentos. Para a análise destes dados foi elaborada uma escala do grau de pressão que os fragmentos exercem sobre a matriz (GRISE, 2008): que 1,5 ;

a) grau de pressão 1: índice de forma menor 1,5 e 2,0 ;

b) grau de pressão 2: índice de forma entre que 2,0.

c) grau de pressão 3: índice de forma maior

Essa escala foi baseada em Forman e Godron (1986) e Forman (1995). Os autores expõem a fórmula de cálculo do índice de forma e apresentam a interpretação dos valores obtidos. Valores próximos a 1,0 representam formas mais circulares (1,0 representa a forma de um círculo perfeito), enquanto valores como 3 e 4 representam formas bastante irregulares, considerando que quanto mais irregular a forma de um fragmento maior será sua área afetada pela borda e, consequentemente, menor 
será sua área de interior.

\section{Análise da estrutura da paisagem}

Após a classificação e definição das classes de cobertura do solo e dos atributos de cada polígono formado, esses foram analisados e relacionados uns com os outros. A quantidade de polígonos referente a cada classe de cobertura do solo, em relação às classes de área de cobertura e às classes de perímetro.

A matriz foi definida segundo o método da área relativa proposto por Forman e Godron (1986). A classe de cobertura do solo de maior área foi definida como a matriz da paisagem. Após a definição da matriz, todos os demais polígonos foram definidos como fragmentos. Os corredores não foram abordados por este trabalho.

A Zona de Amortecimento do Parque foi definida em $10 \mathrm{Km}$, seguindo o proposto pela Resolução do Conselho Nacional do Meio Ambiente (CONAMA) No 13/90, de 6 de dezembro de 1990, em seu Art. $2^{\circ}$. Foram criados buffers de $10 \mathrm{Km}$ a partir do limite do PN e verificado o uso do solo nesta área.

\section{RESULTADOS E DISCUSSÃO}

\section{Processamento da imagem digital}

A utilização das imagens digitais Landsat 5 TM com resolução espacial de $30 \mathrm{~m}$ para a realização da análise da estrutura da paisagem do PN do Superagüi e de sua Zona de Amortecimento, se mostrou satisfatória. Numa área de 175.992,64 ha foram definidos polígonos representando as classes de cobertura do solo.

A área de estudo possui predominantemente cobertura vegetal. A partir da composição das bandas espectrais do vermelho, infravermelho próximo e infravermelho médio, pode-se estabelecer o estado da vegetação, uma vez que a vegetação sadia reflete intensamente no infravermelho próximo, e sua absorção no vermelho é alta (NOVO, 1992), definindo-se as classes vegetação nativa e vegetação alterada.

Houve dificuldade de separar espectralmente as áreas com presença de areia das áreas urbanas. Para tal foram aplicados os Índices de Artificialidade DoA e NandA que permitiram a elaboração de uma máscara representando as porções de areia presente na área de estudo. Segundo Tedesco et al. (2000) as imagens Landsat se tornam adequadas, uma vez que podem ser visualizadas em várias combinações de bandas espectrais, possibilitando análises mais detalhadas, principalmente quando comparadas às fotografias aéreas. Assim, a imagem Landsat 5 TM apresentou tanto a resolução espacial quanto as bandas necessárias para a correta interpretação dos dados, para a realização deste trabalho.

A realização da correção geométrica, das cenas 220/078 e 220/079 em mosaico, apresentou o RMS (Root Mean Square, ou Erro Médio Quadrático) total de 0,73 pixel, equivalente a 21,90 m. O RMS total foi aceitável, uma vez que é inferior a $30 \mathrm{~m}$ ou 1 pixel. Um valor pequeno de RMS significa que o modelo utilizado é adequado para modelar a relação entre as coordenadas de imagem e geodésicas dos pontos de controle, não apresentando erros grosseiros (CENTENO, 2003).

As amostras de treinamento foram $97 \mathrm{e}$ passaram pela análise da acurácia, através da matriz de confusão. $\mathrm{O}$ acerto de pixels das diferentes classes das amostras de treinamento foi $100 \%$, ou seja, não houve confusão entre as amostras de treinamento estabelecidas. A matriz de confusão apresenta a distribuição de porcentagem de pixels classificados correta e erroneamente. Uma matriz de classificação ideal deve apresentar os valores da diagonal principal próximos a $100 \%$, indicando que não houve confusão entre as classes. Segundo Centeno (2003), é uma medida quantitativa de exatidão da classificação, quanto mais o índice se aproxima de $100 \%$, melhor é considerada a classificação.

\section{Análise da estrutura da paisagem}

O PN do Superagüi possui uma área de 33.855 ha, segundo seu decreto de criação (BRASIL, 1989). Esta UC de Proteção Integral tem como objetivo proteger e preservar os ecossistemas da região, proporcionando o uso controlado dos recursos por meio do turismo, educação e pesquisa. A delimitação realizada para a área de ocupação do Parque totalizou $34.453,47$ ha, incluindo sua ampliação de limite conforme a Lei $\mathrm{N}^{\circ} 9.513$ (BRASIL, 1997). Foram encontradas as classes de cobertura do solo de vegetação nativa, vegetação alterada, solo descoberto, área urbanizada, água e areia (Figura 2).

A grande maioria da cobertura do solo (98,48\%) foi representada pelas classes vegetação nativa, água e areia. Áreas urbanizadas, solo descoberto e vegetação alterada representaram apenas $1,52 \%$ do Parque. A matriz da paisagem foi definida pela classe de vegetação nativa, a qual representou $92,86 \%$ de área de cobertura do solo (Tabela 1). Segundo Forman (1995), a matriz é o 
Grise, M. M.; Biondi, D.

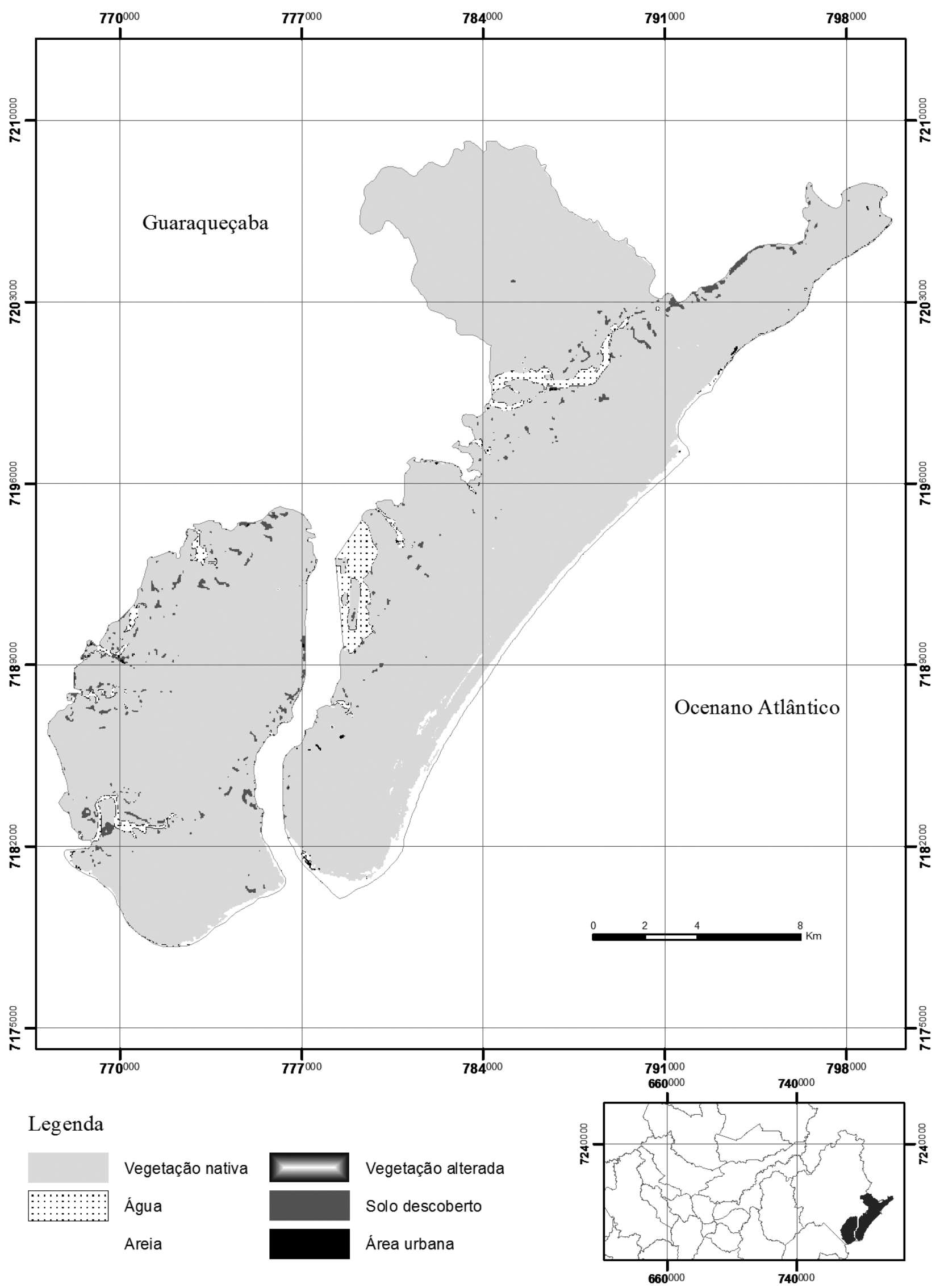

FIGURA 2: Classes de cobertura do solo do PN do Superagüi.

FIGURE 2: Land cover classes of National Park of Superagüi. 
pano de fundo da paisagem que abrange uma extensa área, de grande conectividade, e tem o controle da dinâmica da paisagem cercando e afetando os fragmentos e os corredores. É de extrema importância por controlar a dinâmica da paisagem, servindo de fonte de informações para diversas funções ecológicas de plantas e animais. A matriz tem o maior controle da paisagem e da dinâmica regional (FORMAN, 1995) e é um complemento essencial para assegurar a proteção da diversidade biológica (FONSECA et al., 1997). Assim, a matriz do Parque, sendo representada pela classe de uso do solo de vegetação nativa, assegura a conservação de suas espécies e ecossistemas.

A porosidade da matriz do Parque foi representada pela presença de 894 fragmentos. Estimando-se a sua densidade sem considerar sua localização, seu tamanho e forma, são 2,6 fragmentos a cada 100 ha. Segundo Grise (2008), esta porosidade pode ser considerada média, comparando-se com a porosidade das demais UCs localizadas no litoral norte do Paraná, como as APAs Federal e Estadual de Guaraqueçaba.

TABELA 1: Classes de cobertura do solo do PN do Superagüi.

TABLE 1: Land cover classes of National Park of Superagüi.

\begin{tabular}{lcc}
\hline $\begin{array}{l}\text { Classes de cobertura } \\
\text { do solo }\end{array}$ & $\begin{array}{l}\text { Área de } \\
\text { ocupação (ha) }\end{array}$ & $\begin{array}{l}\text { Área de } \\
\text { ocupação (\%) }\end{array}$ \\
\hline Água & $1.108,84$ & 3,22 \\
Área urbanizada & 32,33 & 0,09 \\
Areia & 826,90 & 2,40 \\
Solo descoberto & 487,26 & 1,41 \\
Vegetação alterada & 4,48 & 0,01 \\
Vegetação nativa & $31.993,66$ & 92,86 \\
\hline Total & $34.453,47$ & 100,00 \\
\hline
\end{tabular}

Foram encontrados 894 fragmentos, totalizando $2.459,81$ ha, cerca de $7 \%$ da área. Destes, pouco menos da metade (45,97\%) formados por água (Tabela 2). Os fragmentos de solo descoberto apresentaram $37,47 \%$ do total de fragmentos, seguido por areia $-8,28 \%$, pelas áreas urbanizadas $-6,49 \%$ e vegetação alterada $-1,79 \%$. A maioria dos fragmentos (80,98\%) apresentou área menor que 1,0 ha. Apenas 21 fragmentos (2,46\%) possuem área maior que 10 ha; são $10(\mathrm{dez})$ grandes fragmentos de água e 6 (seis) de areia e de solo descoberto.

Os fragmentos de área urbanizada, cerca de $6,5 \%$, são formados por comunidades caiçaras que residem no Parque (Tabela 2), e são os que maior impacto causam na matriz de vegetação nativa. Entretanto, até mesmo as áreas antropizadas podem ser importantes para manter o equilíbrio biótico de uma região, uma vez que já fazem parte da paisagem a séculos. Atualmente existe um reconhecimento crescente de que o envolvimento da população local é o elemento principal que está faltando nas estratégias de manejo de conservação (PRIMACK; RODRIGUES, 2001). Vivekananda (2001) expõe a relação das comunidades caiçaras com este Parque e relata a história de ocupação da região. Segundo a autora, a ocupação humana da região se materializa desde os anos de 1.500 pela presença de sambaquis. A supressão e submissão indígena à colonização, o período de ocupação por fazendas agropecuárias dos jesuítas, a colonização suíça até a atual ocupação de simples e modestas colônias de pescadores.

Ainda que não seja permitida a permanência de comunidades humanas em uma UC de Proteção Integral (BRASIL, 2000), os Parques brasileiros não retratam tal realidade. Os fragmentos de áreas urbanas no PN do Superagüi são regiões ocupadas por comunidades humanas que residem no Parque. Vivekananda (2001) verificou em entrevistas com estas comunidades, que a criação do Parque não

TABELA 2: Número de fragmentos em cada classe de área do PN do Superagüi.

TABLE 2: Number of patches in each class area of National Park of Superagüi.

\begin{tabular}{llllllll}
\hline Classes de & \multicolumn{3}{l}{ Classes de cobertura do solo } & & \multirow{2}{*}{ Total } & \multirow{2}{*}{ Total (\%) } \\
\cline { 2 - 7 } área (ha) & Ága & Área urbanizada & Areia & Solo descoberto & Vegetação alterada & & \\
\hline$<1,0$ & 370 & 50 & 60 & 229 & 15 & 724 & 80,98 \\
1,0 a 10 & 31 & 8 & 8 & 100 & 1 & 148 & 16,55 \\
$>10$ & 10 & 0 & 6 & 6 & 0 & 22 & 2,46 \\
\hline Total & 411 & 58 & 74 & 335 & 16 & 894 & 100,00 \\
\hline Total (\%) & 45,97 & 6,49 & 8,28 & 37,47 & 1,79 & 100,00 \\
\hline
\end{tabular}


significou alteração alguma na rotina das pessoas, que a agricultura de subsistência, bem como a economia baseada na extração de palmito, caxeta e samambaia deixaram de ser a atividade econômica principal dez anos antes da criação do Parque. Fato importante, uma vez que a autora constatou um aumento na área de vegetação nativa em função da diminuição das áreas agrícolas. Entretanto, a extração de recursos naturais, seja para subsistência ou economia, ainda existe e são impactantes e conflitantes ao objetivo de conservação do Parque (VIVEKANANDA, 2001).

Os fragmentos que interrompem a matriz são, na maioria, formados por água e areia, classes de cobertura do solo que podem ser consideradas de origem natural, uma vez que se trata de uma área formada por ilhas. A areia e a água são faixas que percorrem o contorno das Ilhas. As regiões de solo descoberto podem ser áreas de restinga esparsa, onde a resposta espectral da areia com vegetação rasteira esparsa pode ser classificada como solo descoberto, entretanto tal aferição de capo não foi realizada.

É interessante ressaltar que quando se estuda a paisagem de uma Unidade de Conservação qualquer está se trabalhando com uma paisagem cuja matriz de vegetação natural é interrompida pela presença de fragmentos antropizados. Neste caso, ocorre o efeito de borda inverso, onde são os fragmentos que pressionam a matriz. Assim, são os fragmentos de origem antrópica, considerados estáveis e persistentes, que pressionam a matriz de vegetação nativa e interferem em sua estabilidade, dinâmica e área (GRISE, 2008). Como o PN do Superagüi é uma UC de proteção integral, é fundamental identificar os fragmentos e a matriz da paisagem para direcionar as ações de manejo da área.

Em relação às classes de perímetro, 60,29\% dos fragmentos possuem índice de forma menor que 1,5 de grau de pressão 1 (Tabela 3). $\mathrm{O}$ índice de forma próximo a 1 indica que os fragmentos têm forma mais arredondada, que minimizam a relação borda/área (PRIMACK; RODRIGUES, 2001), assim possuem menos área de borda que afeta e, em longo prazo, altera a matriz de vegetação nativa. A predominância de fragmentos de forma irregular da classe água deve-se ao fato do PN ser formado pelas ilhas do Superagüi, das Peças, e de Pinheiro e Pinheirinho; e ainda por uma porção de continente. Os fragmentos de água são de origem natural, assim como os fragmentos de areia. Alguns fragmentos classificados como solo descoberto também pode ser de origem natural, correspondendo às áreas de restinga esparsa.

Os cálculos da média, mediana e moda do índice de forma dos fragmentos quase não ultrapassaram o valor de 1,5 , considerado de grau de pressão 1 , sendo o que menos impacto tem sobre a matriz (Tabela 4). Uma vez que a matriz é de vegetação nativa, a incidência de fragmentos com a relação perímetro/área próximos a 1 (um) é o ideal, pois menor será o efeito de borda destes fragmentos sobre a matriz de vegetação nativa. $\mathrm{O}$ microambiente na borda do fragmento é diferente daquele no interior da floresta. O aumento do nível de luz, temperatura, umidade e vento alteram a flora e a fauna adaptadas às condições de interior da floresta, são frequente e rapidamente eliminadas mudando a composição das espécies (PRIMACK RODRIGUES, 2001).

As classes que apresentaram a maior média e mediana para o índice de forma foram justamente as classes de água, areia e solo descoberto, as quais formam faixas que acompanham o contorno das Ilhas. Estes não estão impactando a matriz, mas sim fazendo parte da paisagem litorânea, natural da região.

TABELA 3: Número de fragmentos em cada classe de perímetro do PN do Superagüi.

TABLE 3: Number of patches in each perimeter class of National Park of Superagüi.

\begin{tabular}{|c|c|c|c|c|c|c|c|}
\hline \multirow{2}{*}{$\begin{array}{l}\text { Classes de perímetro } \\
\text { (índice de forma) }\end{array}$} & \multicolumn{5}{|c|}{ Classes de cobertura do solo } & \multirow[b]{2}{*}{ Total } & \multirow{2}{*}{$\begin{array}{l}\text { Total } \\
(\%)\end{array}$} \\
\hline & Água & $\begin{array}{l}\text { Área } \\
\text { urbanizada }\end{array}$ & Areia & $\begin{array}{l}\text { Solo } \\
\text { descoberto }\end{array}$ & $\begin{array}{l}\text { Vegetação } \\
\text { alterada }\end{array}$ & & \\
\hline$<1,5$ & 200 & 48 & 56 & 219 & 16 & 539 & 60,29 \\
\hline 1,5 a 2,0 & 120 & 7 & 7 & 94 & 0 & 228 & 25,50 \\
\hline$>2,0$ & 91 & 3 & 11 & 22 & 0 & 127 & 14,21 \\
\hline Total & 411 & 58 & 74 & 335 & 16 & 894 & 100,00 \\
\hline Total $(\%)$ & 45,97 & 6,49 & 8,28 & 37,47 & 1,79 & 100,00 & \\
\hline
\end{tabular}

Ci. Fl., v. 22, n. 1, jan.-mar., 2012 
TABELA 4: Índice de forma dos fragmentos do PN do Superagüi.

TABLE 4: Patch shape index of National Park of Superagüi.

\begin{tabular}{lccc}
\hline $\begin{array}{l}\text { Classes de cobertura do } \\
\text { solo }\end{array}$ & $\begin{array}{l}\text { Média do índice de } \\
\text { forma dos fragmentos }\end{array}$ & $\begin{array}{c}\text { Mediana do índice de } \\
\text { forma dos fragmentos }\end{array}$ & $\begin{array}{c}\text { Moda do índice de } \\
\text { forma dos fragmentos }\end{array}$ \\
\hline Água & 1,76 & 1,51 & 1,37 \\
Área urbanizada & 1,33 & 1,20 & 1,13 \\
Areia & 1,59 & 1,20 & 1,13 \\
Solo descoberto & 1,45 & 1,38 & 1,20 \\
Vegetação alterada & 1,24 & 1,20 & 1,13 \\
\hline
\end{tabular}

\section{Zona de amortecimento (ZA)}

A zona de amortecimento do PN do Superagüi não foi estabelecida em seu decreto de criação, até mesmo porque a data de criação do SNUC (que determina a instituição da zona de amortecimento no ato de criação de uma UC) é posterior à criação do Parque. Portanto foi acatada para a realização deste trabalho a Resolução do CONAMA N ${ }^{\circ}$ 13/90, de 6 de dezembro de 1990, em seu Art. $2^{\circ}$ estabelece que nas áreas circundantes das Unidades de Conservação, num raio de 10 $\mathrm{Km}$, qualquer atividade que possa afetar a biota, deverá ser obrigatoriamente licenciada pelo órgão ambiental competente (BRASIL, 1990). Segundo Bensusan (2006), o Roteiro Metodológico de
Planejamento, criado pelo IBAMA em 2002, contém um conjunto de critérios para inclusão e exclusão de áreas na ZA e sugere os $10 \mathrm{Km}$ estabelecidos, pela resolução do CONAMA, como ponto de partida.

O PN está inserido nos limites da APA Federal de Guaraqueçaba. Considerando $10 \mathrm{Km}$ de raio de zona de amortecimento do PN (Figura 3), cerca de $61 \%$ da área encontra-se fora da área da APA Federal de Guaraqueçaba (Tabela 5). Grande parte deste percentual são áreas marinhas. Um dos pressupostos de uma APA é servir de zona de amortecimento para as UCs de Proteção Integral. Entretanto, o PN foi criado depois da APA Federal de Guaraqueçaba.

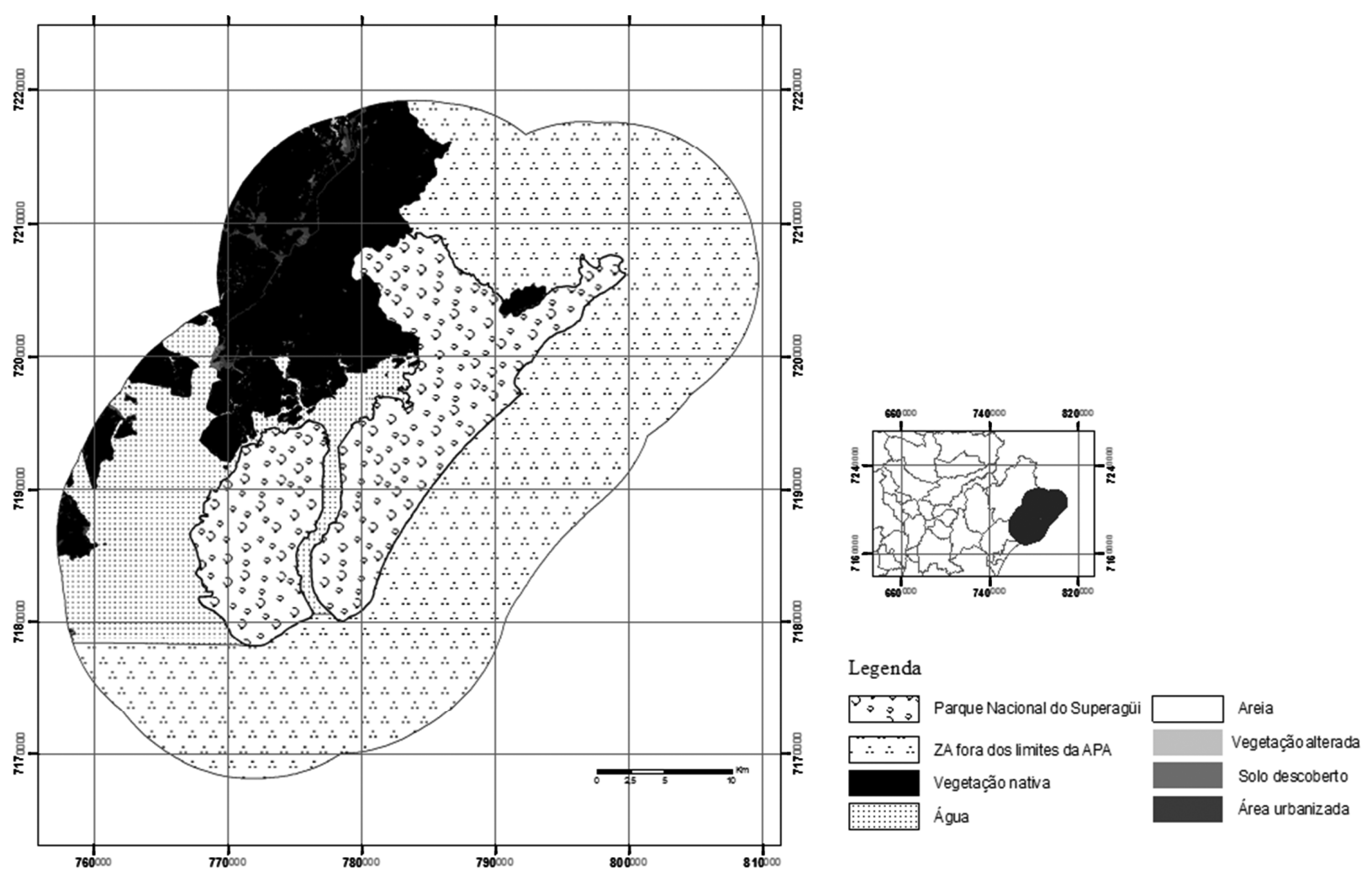

FIGURA 3: Cobertura do solo da zona de amortecimento do PN do Superagüi.

FIGURE 3: Buffer zone land cover of National Park of Superagüi. 
TABELA 5: Cobertura do solo da zona de amortecimento do PN do Superagüi.

TABLE 5: Buffer zone land cover of National Park of Superagüi.

\begin{tabular}{lccr}
\hline Classes de cobertura do solo & $\begin{array}{c}\text { Número de } \\
\text { polígonos }\end{array}$ & $\begin{array}{c}\text { Área de ocupação } \\
\text { (ha) }\end{array}$ & $\begin{array}{c}\text { Área de ocupação } \\
(\%)\end{array}$ \\
\hline Área da ZA do PN fora da APA & 1 & $85.915,29$ & 60,72 \\
Água & 32 & $23.822,33$ & 16,84 \\
Área urbanizada & 142 & 863,86 & 0,61 \\
Areia & 8 & 21,31 & 0,02 \\
Solo descoberto & 482 & 382,21 & 0,27 \\
Vegetação alterada & 226 & 110,86 & 0,08 \\
Vegetação nativa & 81 & $30.379,15$ & 21,47 \\
\hline Total & 972 & $141.495,01$ & 100,00 \\
\hline
\end{tabular}

O observado para a zona de amortecimento do PN do Superagüi, o qual não contempla as áreas marinhas, vem ao encontro da necessidade de aumentar a conservação dos componentes marinhos e costeiros das áreas protegidas. Uma discussão que se faz presente nas reuniões mundiais, a respeito da proteção de áreas naturais, é a inclusão de áreas marinhas nos sistemas de conservação. Tal discussão é pertinente quando se verifica que pouquíssimas reservas naturais incluem porções marinhas em seus limites. Das mais de 5.000 áreas protegidas do mundo, apenas 1.300 incluem componentes marinhos e costeiros (PRATES, 2009), correspondendo a cerca de, aproximadamente, $0,6 \%$ da área da superfície oceânica e cerca de $1,4 \%$ das áreas de plataforma continental protegidas $(\mathrm{CDB}$, 2006). Segundo dados do Ministério do Meio Ambiente, em 2009 apenas 1,46\% dos cerca de 4,5 mil quilômetros quadrados de oceanos, sob jurisdição brasileira, estavam sob proteção (REDE PRÓ-UC, 2009).

Menos de 1\% dos fragmentos encontrados na ZA, que coincide com a área da APA Federal de Guaraqueçaba, são de vegetação alterada, áreas antropizadas e solo exposto. São estes fragmentos que devem ser sujeitos a normas e restrições de uso para que minimizem os impactos negativos sobre o Parque.

\section{CONCLUSÕES}

O uso da imagem Landsat $5 \mathrm{TM}$, de resolução espacial de $30 \mathrm{~m}$, se mostrou satisfatória para classificar a cobertura do solo do Parque e de sua zona de amortecimento.

A caracterização e a análise da estrutura da paisagem, através dos componentes matriz e fragmentos, serviram de base para a verificação da funcionalidade da cobertura do solo do Parque.

Considera-se o Parque Nacional do Superagui uma UC muito importante e representativo da biota regional, uma vez que sua matriz, formada pela classe de vegetação nativa, detém a dinâmica da paisagem garantindo assim os fluxos de matéria, energia e espécies pela área em questão.

A zona de amortecimento do Parque Nacional do Superagüi não está contemplada, em sua totalidade, pela área da APA Federal de Guaraqueçaba, cujo objetivo é proteger o entorno das UCs de Proteção Integral.

As áreas marinhas ao redor do Parque Nacional do Superagüi não estão incluídas nas delimitações da APA Federal de Guaraqueçaba. Sugere-se que as áreas marinhas sejam incorporadas às delimitações da APA Federal de Guaraqueçaba, visando não só a conservação da biodiversidade, mas também a recuperação dos estoques pesqueiros da região.

\section{REFERÊNCIAS BIBLIOGRÁFICAS}

\section{BENSUSAN, N. Conservação da biodiversidade} em áreas protegidas. Rio de Janeiro: FGV, 2006.

BRASIL. Decreto n. 90.883, de 31 de janeiro de 1985. Dispõe sobre a implantação da Área de Proteção Ambiental de Guaraqueçaba. Diário Oficial da União, Brasília, 31 de janeiro de 1985.

BRASIL. Decreto n. 97.688 de 25 de abril de 1989. Cria o Parque Nacional do Superagüi. Diário Oficial da União, Brasília, 25 de abril de 1989.

BRASIL. Ministério do Meio Ambiente. Resolução do Conselho Nacional do Meio Ambiente CONAMA n. 13 de 6 de dezembro de 1990. Diário Oficial da União, Brasília, 6 de dezembro de 1990. BRASIL. Lei n. 9.513 de 20 de novembro de 1997. Amplia os limites do Parque Nacional do Superagüi, 
criado pelo Decreto n ${ }^{\circ}$ 97.688, de 25 de abril de 1989. Diário Oficial da União, Brasília, 20 de novembro de 1997.

BRASIL. Lei n. 9.985, de 18 de julho de 2000. Regulamenta o artigo 225, § $1^{\circ}$, incisos I, II, III e VII da Constituição Federal, institui o Sistema Nacional de Unidades de Conservação da Natureza e dá outras providências. Diário Oficial da União, Brasília, 19 de julho de 2000.

CDB. Panorama da Biodiversidade Global 2. Montreal: Secretariado da Convenção de Diversidade Biológica. 2006.

CENTENO, J. A. S. Sensoriamento Remoto e Processamento de Imagens Digitais. Curitiba: UFPR, 2003. 210 p.

FORMAN, R. T. T. Land Mosaics: the ecology of landscapes and regions. New York: Cambridge University Press, 1995.

FORMAN, R. T. T.; GODROM, M. Landscape ecology. New York: J. Wiley, 1986.

GRISE, M. M. A estrutura da paisagem do mosaico de unidades de conservação do litoral norte do Paraná. 2008. Dissertação (Mestrado em Engenharia Florestal)-Universidade Federal do Paraná, 2008.

IAP - Instituto Ambiental do Paraná. Programa de desenvolvimento sustentável da Área de Proteção Ambiental de Guaraqueçaba. Curitiba: Universidade Livre do Meio Ambiente, Sociedade de Pesquisa em Vida Selvagem e Educação Ambiental, 1999.

IPARDES - Instituto Paranaense de Desenvolvimento Econômico e Social. Diagnóstico ambiental da Área de Proteção Ambiental de Guaraqueçaba. Curitiba: IPARDES, 1995.

IPARDES - Instituto Paranaense de Desenvolvimento Econômico e Social. Zoneamento da Área de Proteção Ambiental de Guaraqueçaba. Curitiba: IPARDES, 2001.

NOVO, E. M. L. de M. Sensoriamento Remoto: princípios e aplicações. 2. ed. São Paulo: E. Blucher, 1992.

PRATES, A. P. L. Unidades de conservação costeiras e marinhas como instrumento de gestão pesqueira. In: CONGRESSO BRASILEIRO DE UNIDADES DE CONSERVAÇÃO, 6., 2009, Curitiba. Anais... Curitiba: Rede Nacional Pró-Unidades de Conservação, 2009. 1 CDROM.

REDE PRÓ-UC. Oceanos esquecidos. In: http:// www.redeprouc.org.br/site2009/noticia-pq. asp?codigo=369. Acesso em: 2009.

PRIMACK, R. B.; RODRIGUES, E. Biologia da conservação. 3. ed. Londrina: Editora Vida, 2002.

SPVS - Sociedade de Pesquisa em Vida Selvagem e Educação Ambiental. Plano integrado de conservação para a região Guaraqueçaba, Paraná, Brasil. Curitiba: Sociedade de Pesquisa em Vida Selvagem e Educação Ambiental, 1992.

TEDESCO, A.; et al. Uso das técnicas de posicionamento por satélite e sensoriamento remoto para monitoramento do impacto ambiental decorrente da ação antrópica na região de Matinhos (PR). Curitiba, 2000. Trabalho acadêmico (Projeto final)-Curso de Engenharia Cartográfica, Departamento de Geomática, Universidade Federal do Paraná.

TOSSULINO, M. de G. P.; MUCHAILH, M. C.; CAMPOS, J. B. A importância do correto enquadramento das Unidades de conservação para a sua efetividade. In: CAMPOS, J. B.; TOSSULINO, M. de G. P.; MÜLLER, C. R. (org.). Unidades de Conservação: ações para valorização da biodiversidade. Curitiba: Instituto Ambiental do Paraná, 2006. p. 259-277.

VIVEKANANDA, G. Parque Nacional do Superagüi: presença humana e os objetivos de conservação. 2001. Dissertação (Mestrado em Engenharia Florestal)-Setor de Ciências Agrárias, Universidade Federal do Paraná, Curitiba, 2001. 